\title{
Single-chain human chorionic gonadotropin analogs containing the determinant loop of the $\beta$-subunit linked to the $\alpha$-subunit
}

\author{
R L Schubert and D Puett \\ Department of Biochemistry and Molecular Biology, University of Georgia, Athens, Georgia 30602, USA \\ (Requests for offprints should be addressed to D Puett, Department of Biochemistry and Molecular Biology, B129 Life Sciences Building, \\ 120 Green Street, University of Georgia, Athens, GA 30602-7229, USA; Email: puett@bmb.uga.edu)
}

\begin{abstract}
Human chorionic gonadotropin (hCG) is a member of the family of glycoprotein hormones containing a common $\alpha$-subunit and distinct $\beta$-subunits that confer hormonal specificity. hCG binds to the relatively large ectodomain of the human luteinizing hormone receptor (hLHR), a member of the G protein-coupled receptor superfamily, leading to increased intracellular production of cAMP. Using protein engineering, two miniaturized versions of hCG $\beta$ have been separately fused to the $\mathrm{N}$-terminus of the $\alpha$-subunit to give $\mathrm{N}-\operatorname{des}[1-91] \mathrm{hCG} \beta-\alpha-\mathrm{C}$ and $\mathrm{N}-\operatorname{des}[1-91,110-114] \mathrm{hCG} \beta-\alpha-\mathrm{C}$, i.e. fusion proteins of the hCG $\beta$ determinant loop (extended to include the complete seat belt and carboxy-terminal peptide) coupled to the $\alpha$-subunit. Bioactivity of these single-chain gonadotropin analogs was assessed in two systems following transient transfections into HEK 293 cells and subsequent cAMP measurements. In one, each mini- $\beta-\alpha$ cDNA was fused to that of hLHR and transfected into cells to create yoked miniaturized hCG-hLHR complexes; in the other, the cDNA of each single chain mini- $\beta-\alpha$ was co-transfected with that of hLHR in an effort to produce non-covalent miniaturized hCG-hLHR complexes. Using yoked hCG-hLHR and hLHR as positive and negative controls respectively, expression of each mini-hCG-hLHR complex was confirmed using antibody and ligand binding assays. The two mini-hCGs led to minimal activation of hLHR, suggesting weak intrinsic activity of the mini- $\beta-\alpha$ fusion proteins. These results suggest that potent agonists and antagonists will require the presence of other portions of hCG $\beta$ in addition to the determinant loop/seat belt.
\end{abstract}

Journal of Molecular Endocrinology (2003) 31, 157-168

\section{Introduction}

The four human (h) glycoprotein hormones are heterodimers that share a common $\alpha$-subunit, comprised of 92 amino acid residues, and a distinct $\beta$-subunit that confers hormonal specificity (Hearn \& Gomme 2000). The $\beta$-subunit of human chorionic gonadotropin (hGG) contains 145 amino acid residues, including a 30 residue extension at its $\mathrm{C}$-terminus, referred to as the $\mathrm{C}$-terminal peptide (CTP). The four hormones act via three $\mathrm{G}$ protein-coupled receptors, with the $\beta$-subunits of hGG and luteinizing hormone (LH) being sufficiently similar that the two gonadotropins both bind to and activate the LH receptor (hLHR) (Dufau 1998, Ascoli et al. 2002).
hCG is the most comprehensively studied of the human glycoprotein hormones, and therefore there is an abundance of information available concerning the regions of the two subunits believed to be important for bioactivity. Using various techniques such as site-directed mutagenesis (Chen \& Puett 1991a,b, Chen et al. 1991, 1992, Bielinski \& Boime 1992, Liu et al. 1993, Yoo et al. 1993, Puett et al. 1994, Puett \& Narayan 2000), protein chimeras (Campbell et al. 1991, Dias et al. 1994, Han et al. 1996, Grossmann et al. 1997), and synthetic peptides (Salesse et al. 1990, Keutmann 1992), many of the regions of hGG important for heterodimer formation and receptor binding and activation have been determined, as well as the suggestion that both subunits are required for full 
activity. The combined findings from these studies concerning ligand-receptor interactions have indicated that the central portion of the $\alpha$-subunit and the determinant loop (Moore et al. 1980) of hCG $\beta$ (residues 93-100), i.e. the N-terminal portion of the $\beta$-seat belt (Lapthorn et al. 1994, Wu et al. 1994), are required for LHR binding and activation, although whether the determinant loop directly contacts the receptor remains controversial (Han et al. 1996). The importance of this region in glycoprotein receptor discrimination confirms earlier predictions based upon amino acid sequence comparisons of the glycoprotein hormone $\beta$-subunits (Moore et al. 1980). The crystal structure of aglyco-hCG (Lapthorn et al. 1994, Wu et al. 1994), followed by that of human follicle-stimulating hormone (hFSH) (Fox et al. 2001), demonstrated that the regions of $\alpha$ and $\beta$, delineated as putative receptor contact sites, are in relatively close proximity to one another.

We and others have shown that biologically active fusion proteins of hCG could be constructed in the manner N-hCG $\beta-\alpha-\mathrm{C}$ (Narayan et al. 1995, Sugahara et al. 1995, Heikoop et al. 1997, Schubert et al. 2003) and N- $\alpha$-CTP-hCG $\beta-\mathrm{C}$ (Narayan et al. 2000a, Sen Gupta \& Dighe 2000, Ben-Menahem et al. 2001). These studies were expanded to include yoked hCG-rat LHR complexes (YHR) of the form, N-hCG $\beta$ - $\alpha$-CTP-LHR-C (Wu et al. 1996) and N- $\alpha$-hCG $\beta$-LHR-G (Narayan et al. 2000a), resulting in ligand-mediated constitutive receptor activation. The goal of the current investigation is the design and characterization of miniaturized hGG hormones, a continuation of work from this and other laboratories focused on N-terminal and G-terminal deletion mutants of hCG $\beta$ that retained the ability to form heterodimers and activate LHR (El-Deiry et al. 1989, Matzuk et al. 1990, Chen \& Bahl 1991, Chen \& Puett 1991a, Huang et al. 1993a, Slaughter et al. 1995). Currently, the shortest hCG $\beta$ fragment retaining full activity, i.e. capable of holoprotein formation and subsequent LHR activation with equipotency to wild-type hCG, is $\operatorname{des}[1-7,111-145] \mathrm{hCG} \beta$, while $\operatorname{des}[1-$ 7,101-145]hCG associates poorly with $\alpha$; however, the resulting heterodimer exhibits some activity (Huang et al. 1993a). Only three hCG $\beta$ C-terminal deletion fragments have been described in $\beta-\alpha$ single chain gonadotropins, all involving deletion of portions of the CTP, des[124-145] (Wu et al. 1996) and des[103-145] and des[112-145] (Heikoop et al. 1997).

We have created single-chain minigonadotropins in which a large N-terminal portion of hCG $\beta$ has been removed (residues 1-91) and the remainder of the subunit, containing the determinant loop/seat belt region and the CTP, was fused to the $\mathrm{N}$-terminus of the full-length $\alpha$-subunit to create YMG1. YMG2 incorporates a further deletion of hCG $\beta$, residues 110-114, eliminating a portion of the $\mathrm{C}$-terminal region of the seat belt that includes Cys-110, which pairs with Cys-26 in native hCG (Lapthorn et al. 1994, Wu et al. 1994). These deletions were chosen in order to retain the $\beta$-seat belt, deemed important for hormone binding and receptor activation via the determinant loop, as well as the CTP to serve as a linker. However, difficulty was experienced in expressing sufficient quantities of the mini-gonadotropins in mammalian cells for dose-response curves. Based on this limitation and anticipating low affinity interaction of these hCG analogs with LHR, we have used the yoked hormone-receptor system and cotransfection studies to evaluate the activity of the two miniaturized yoked hCG hormones. It was found that each mini-gonadotropin activates hLHR, but only to a very small degree.

\section{Materials and methods}

\section{Construction of yoked mini-gonadotropins and yoked mini-gonadotropin-receptor complexes}

MG1 and MG2 were created using PGRs to generate the hCG $\beta$ fragments in the following manner: MG1: 5'-BamHI restriction site/hCG $\beta$ signal sequence/flag tag/hCG $\beta$ residues 92-145/ EcoRI-3', and MG2: 5'-BamHI restriction site/ hCG $\beta$ signal sequence/flag tag/hCG $\beta$ residues 92-109, 114-145/EcoRI-3'.

In order to create the miniaturized hCG fusion proteins, the N-terminal deletion cDNAs of hCG $\beta$ were ligated in place of full length hCG $\beta$ in $\mathrm{N}-\mathrm{hCG} \beta-\alpha-\mathrm{C}$ to give N-MG1- $\alpha-\mathrm{C}$ (YMG1) and N-MG2- $\alpha-\mathrm{C}$ (YMG2).

A BamHI/EcoRI double digestion was used to excise the miniaturized hCG $\beta$ subunits from YMG1 and YMG2. The full length hCG $\beta$ was then removed from the existing N-hCG $\beta-\alpha-$ LHR-G construct by BamHI/EcoRI digestion. The miniaturized hCG $\beta$ subunits were then ligated 
in place of full length hCG $\beta$ to produce $\mathrm{Y}(\mathrm{MG} 1 / \mathrm{LHR})$ and $\mathrm{Y}(\mathrm{MG} 2 / \mathrm{LHR})$.

\section{Cell culture and transient transfections}

HEK 293 cells were grown in monolayer culture in Dulbecco's modification of Eagle's medium (DMEM) supplemented with 10\% (v/v) newborn calf serum, $10 \mathrm{mM}$ HEPES buffer, $50 \mathrm{U} / \mathrm{ml}$ penicillin, $\quad 50 \mu \mathrm{g} / \mathrm{ml}$ streptomycin, $\quad 50 \mu \mathrm{g} / \mathrm{ml}$ Fungizone, and $0 \cdot 125 \mu \mathrm{g} / \mathrm{ml}$ amphotericin B (Schubert et al. 2003). The cDNAs were transfected into HEK 293 cells using lipofectamine as recommended by Invitrogen Life Technologies (5 $\mu \mathrm{g}$ of each cDNA for each fusion protein; $5 \mu \mathrm{g}$ of each cDNA for each co-transfection for a total of $10 \mu \mathrm{g})$.

\section{Hormone binding}

Approximately 16-18 h after transfection, the cells were resuspended in growth media and added to tissue culture plates coated with $0 \cdot 1 \%$ gelatin in PBS. Approximately $24 \mathrm{~h}$ later the cells were assayed for ${ }^{125} \mathrm{I}-\mathrm{hCG}$ binding as described earlier (Schubert et al. 2003). Briefly, for competitive binding, increasing concentrations of unlabeled hCG (purchased from Dr Albert Parlow (Torrance, CA, USA) and the NIDDK (Bethesda, MD, USA) in Waymouth's media with $0 \cdot 1 \%$ bovine serum albumin (BSA) (w/v) and $50 \mathrm{pM}{ }^{125} \mathrm{I}-\mathrm{hCG}$ were incubated with the cells at $37^{\circ} \mathrm{C}$ for $6 \mathrm{~h}$. Nonspecific binding was determined by addition of $1 \mu \mathrm{g} / \mathrm{ml}$ unlabeled hormone. The cells were washed with PBS, lysed with $1 \mathrm{M} \mathrm{NaOH}$, and counted in a gamma counter. All assays were performed in duplicate, and mock transfected cells were used as a control.

\section{Anti-LHR antibody binding assay}

Approximately 16-18 h after transfection, the cells were processed as described above and the cells assayed for binding of an anti-rat LHR polyclonal antibody (raised against a synthetic peptide to residues 15-38 and kindly provided by Dr Patrick Roche, Mayo Medical School, Rochester, MN, USA) that was detected by secondary ${ }^{125}$ I-antirabbit antibody. The cells were incubated in a $1: 4000$ dilution of the primary antibody in Waymouth's media and $0.3 \%(\mathrm{w} / \mathrm{v}) \mathrm{BSA}$ for
$4 \mathrm{~h}$ while shaking. After washing twice with Waymouth's media and $0 \cdot 3 \%(\mathrm{w} / \mathrm{v}) \mathrm{BSA}$, the cells were incubated with the ${ }^{125} \mathrm{I}$-anti-rabbit secondary antibody (400 000 c.p.m./well) in Waymouth's media and $0.3 \%$ BSA for $1 \mathrm{~h}$ with shaking. After the second incubation period, the cells were washed with PBS and then removed from the plates as described above and counted. Each experiment was performed in duplicate and all steps were performed at room temperature.

\section{cAMP assay}

About 16-18 h after transfection, the cells were replated and washed as described above, then incubated in Waymouth's media with $0 \cdot 1 \%(\mathrm{w} / \mathrm{v})$ BSA and $0.8 \mathrm{mM}$ isobutylmethylxanthine (IBMX) for $15 \mathrm{~min}$ at $37^{\circ} \mathrm{C}$. Following removal of the medium, the cells were incubated with increasing concentrations of hCG for $30 \mathrm{~min}$ at $37^{\circ} \mathrm{C}$ in Waymouth's media containing $0 \cdot 1 \%(\mathrm{w} / \mathrm{v})$ BSA and $0.8 \mathrm{mM}$ IBMX. After removal of the incubation medium, the cells were lysed in $100 \%$ ethanol at $-20^{\circ} \mathrm{C}$ overnight, the extract collected, dried under vacuum, and cAMP concentrations were determined by RIA (Schubert et al. 2003). The results are presented in two units for basal cAMP: $\mathrm{pmol} / \mathrm{ml}$ and $\mathrm{pmol} / \mathrm{fmol}$ bound ${ }^{125} \mathrm{I}-\mathrm{hCG}$, the latter to correct for receptor expression differences. (The correction for receptor expression was based on $\mathrm{B}_{\mathrm{o}}$, i.e. the specific binding of $50 \mathrm{pM}{ }^{125} \mathrm{I}-\mathrm{hCG}$ in which c.p.m. bound was converted to fmol bound. However, since the $K_{\mathrm{d}}$ values of the constructs are the same as that of LHR, this serves as a relative correction for receptor densities. Since no correction was made for transfection efficiency or $\mathrm{B}_{\max }$, the values cannot be considered as absolute pmol cAMP produced per fmol bound hCG in $30 \mathrm{~min}$. On the other hand, transfection efficiencies are comparable within a given assay, and $\mathrm{B}_{\mathrm{o}}$ is directly proportional to $\mathrm{B}_{\max }$ under these conditions. Thus, the relative corrections are valid for comparative purposes.) Each experiment was performed in duplicate.

\section{Data analysis}

Competitive binding and cAMP data were analyzed by non-linear regression using the Prism software program (Graph Pad Software, San Diego, CA, USA). The results are given as 
A.
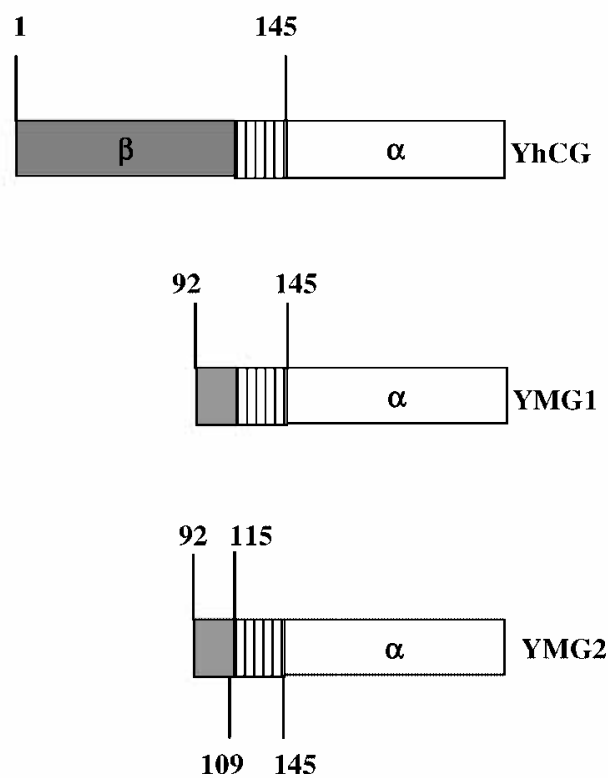

B.

$\mathrm{Y}(\mathrm{CG} / \mathrm{LHR})$

\begin{tabular}{|l|l||l||l||}
\hline$\beta$ & $\alpha$ & $\alpha$ & hLHR \\
\hline
\end{tabular}

Y(MG1/LHR)

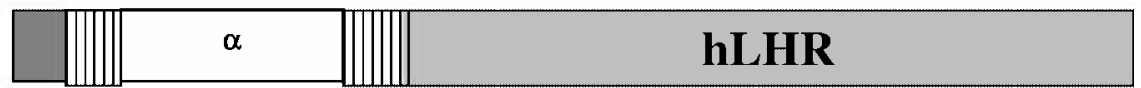

$\mathrm{Y}(\mathrm{MG} 2 / \mathrm{LHR})$

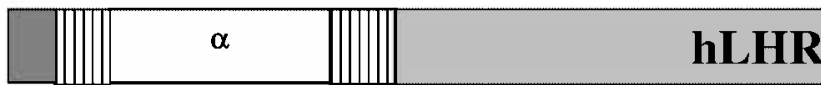

Figure 1 Schematic representation of yoked mini-gonadotropins and yoked hCG-hLHR complexes. (A) YMG1 and YMG2 compared with YhCG with the CTP. YMG1 contains amino acid residues $92-145$ of hCG $\beta$, i.e. residues $92-114$ plus the CTP (residues $115-145$, indicated by vertical stripes), fused to the full length $\alpha$-subunit (92 amino acid residues). YMG2 contains a further deletion of hCG $\beta$ residues 110-114, which removes Cys-110 that is present in YMG1. (B) Y(MG1/LHR) and Y(MG2/LHR) compared with $Y(C G / L H R)$. The CTP is again denoted by vertical stripes. The two sites of $\mathrm{N}$-glycosylation on each of the intact subunits and the four sites of O-glycosylation on the CTP are not shown.

means \pm S.E.M., based on 3-7 independent transfections, and significance $(P<0 \cdot 05)$ was determined by Student's $t$-test. The figures showing competitive binding and hCG-mediated cAMP production are based on overall averages from replicate transfections, and the $\mathrm{IC}_{50} \mathrm{~s}$ and $\mathrm{ED}_{50} \mathrm{~s}$ in Table 1 refer to the average of each individual parameter from each transfection. The $\mathrm{IC}_{50}$ and $\mathrm{ED}_{50}$ values are given in Table 1 in $\mathrm{nM}$ units; by convention, the dose-response curves are presented in $\mathrm{ng} / \mathrm{ml}$ units. To convert the latter to $\mathrm{nM}$, simply multiply by $0 \cdot 027$. 


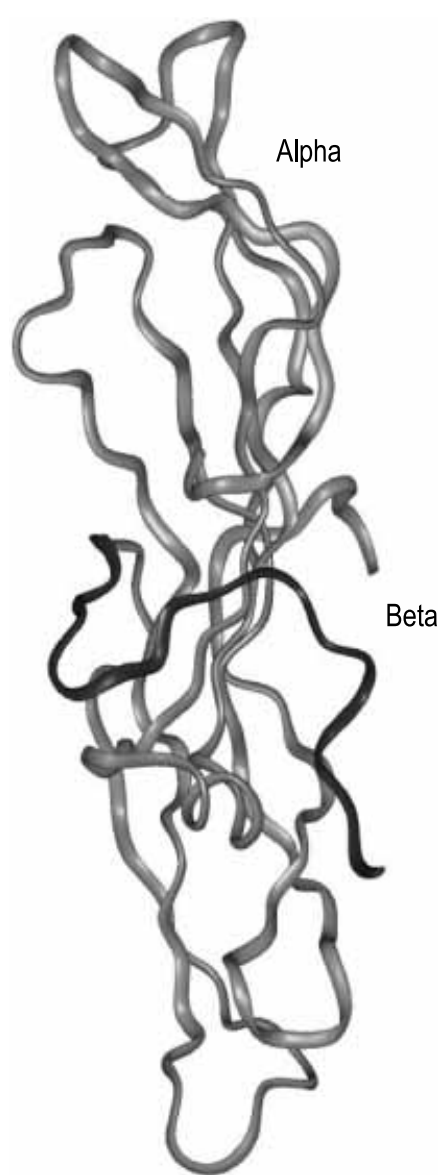

Figure 2 Crystal structure of deglycosylated hCG. The $\alpha$-subunit from residues 5-89 and the $\beta$-subunit from residues $2-111$ are shown. The other amino acid residues did not appear in the electron density maps (Lapthorn et al. 1994, Wu et al. 1994), presumably due to their flexible nature. The region of the miniaturized $\beta$-subunit from residues $92-111$ is highlighted in a darker tone.

\section{Results}

\section{Structures of the yoked mini-hCGs and yoked mini-hCG-hLHR complexes}

Schematics of the two yoked mini-gonadotropins, YMG1 and YMG2, are shown in Fig. $1 \mathrm{~A}$ and compared with YhCG. YMG1 lacks the N-terminal 91 amino acid residues of hGG $\beta$, and thus both sites of $\mathrm{N}$-glycosylation and the Cys-knot cluster, but retains the remainder of the $\beta$-subunit, including the determinant loop-containing seat belt and the CTP with its four sites of O-glycosylation, that is fused to $\alpha$. YMG2 is similar but has an additional five amino acid residue sequence
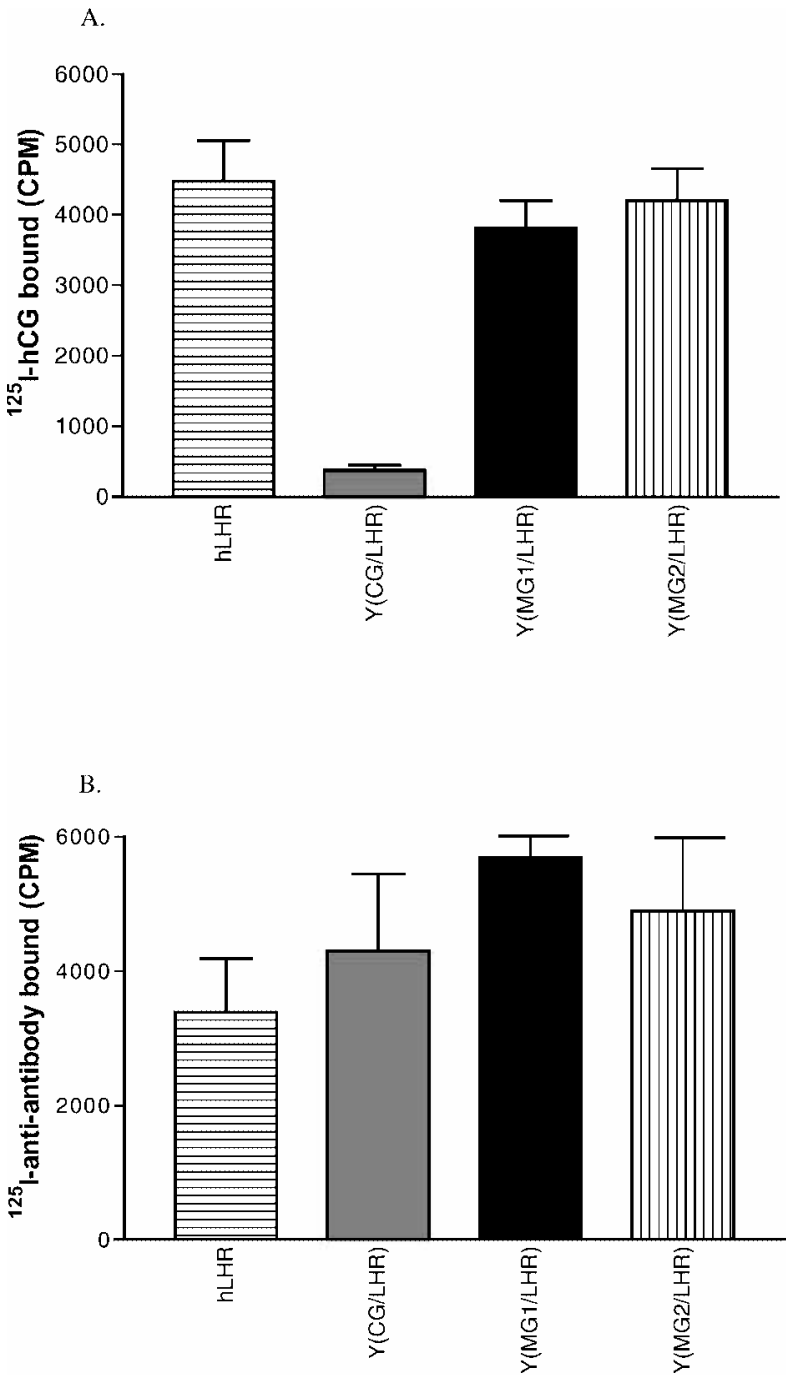

Figure 3 Cell surface expression of hLHR and the yoked ligand-receptor complexes, Y(CG/LHR), $Y(M G 1 / L H R)$, and $Y(M G 2 / L H R)$. (A) Specific binding following addition of $50 \mathrm{pM}{ }^{125}$ I-hCG to HEK 293 cells expressing hLHR and three yoked ligand-receptor complexes. The levels of exogenous ligand binding to hLHR, Y(MG1/LHR), and Y(MG2/LHR) are similar, while Y(CG/LHR), as expected (Wu et al. 1996, Narayan et al. 2000a, 2002), binds negligible amounts of 125I-hCG. (B) Expression of hLHR, free and in yoked complexes, as monitored by a rabbit anti-rat LHR antibody, followed by binding of ${ }^{125} \mathrm{I}$-anti rabbit secondary antibody. The data are corrected for binding to mock-transfected cells, and there are no significant differences between the receptor levels.

deleted, 110-114, hence removing Cys-110 that pairs with Cys-26 in hCG $\beta$. The two yoked mini-gonadotropin-hLHR structures are given 

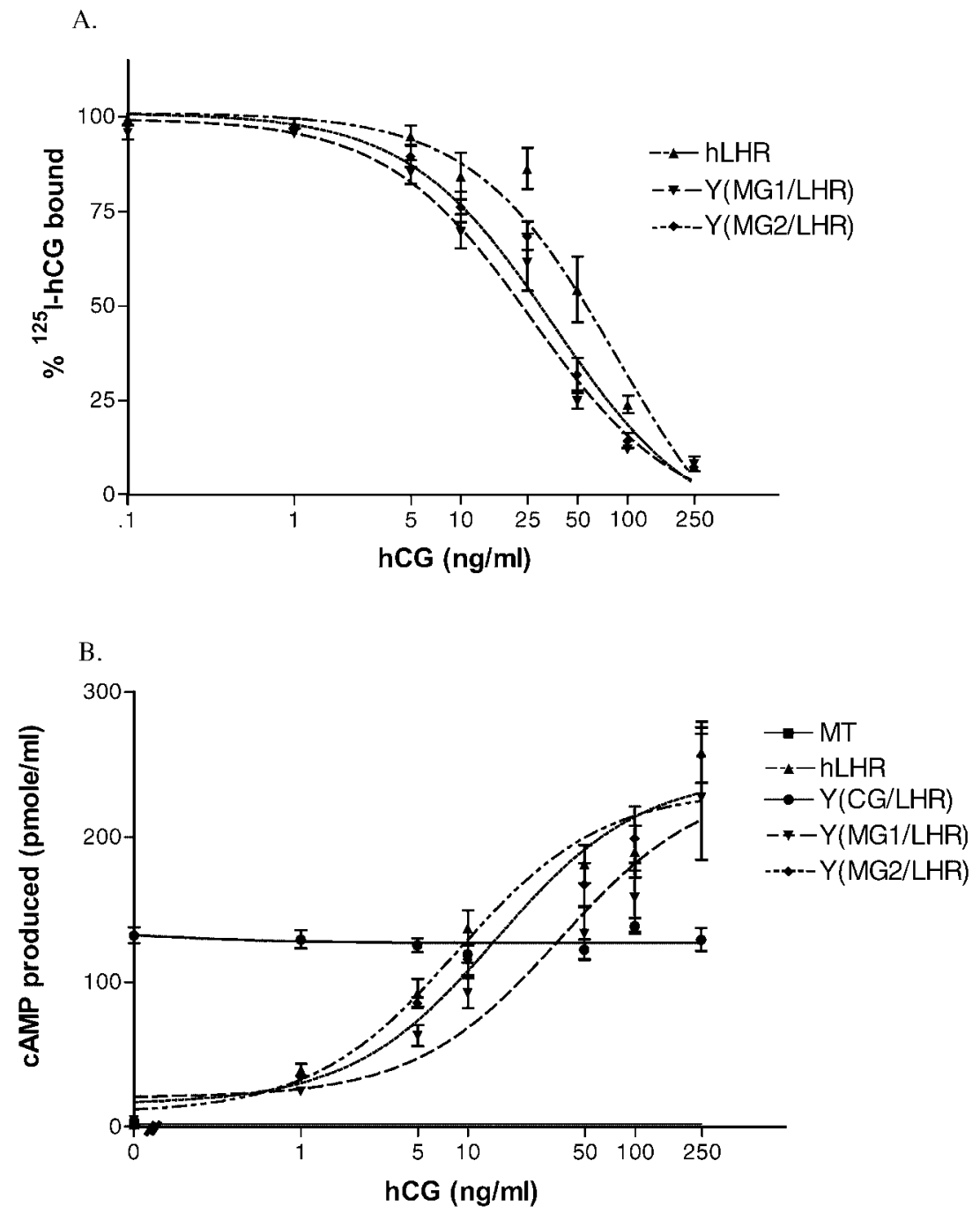

Figure 4 Competitive binding and cAMP dose-response curves with HEK 293 cells expressing hLHR and fusion proteins. (A) Competitive binding with $50 \mathrm{pM}^{125} \mathrm{I}-\mathrm{hCG}$ and various concentrations of unlabeled hCG for hLHR and the two yoked mini-gonadotropin-receptor complexes. (B) CAMP production of mock-transfected (MT) cells and cells expressing hLHR and the three yoked ligand-receptor complexes. The $\mathrm{IC}_{50} \mathrm{~S}$ and $\mathrm{EC}_{50} \mathrm{~S}$ are given in Table 1.

schematically in Fig. $1 \mathrm{~B}$ and compared with that of yoked hCG-hLHR (Y(GG/LHR)). The crystal structure of aglyco-hCG (Lapthorn et al. 1994, Wu et al. 1994) is shown in Fig. 2 with the seat belt of hCG $\beta$ preserved in the mini-gonadotropins highlighted.

Anticipating that any discernible binding of the miniaturized hGG $\beta$ s, fused to $\alpha$, would be of low affinity, experimental conditions were chosen to maximize association with hLHR. One paradigm, based on protein engineering to produce fusion proteins, was developed by our laboratory to give constitutive ligand-mediated receptor activation and involved yoking a single chain hCG to the full length receptor (Wu et al. 1996, Puett \& Narayan 2000, 2002, Narayan et al. 2000a,b, Schubert et al. 2003) and to the receptor ectodomain (Fralish et al. 2001). The former approach was used in the present study with full length hLHR in order to permit an evaluation of receptor activation in transfected HEK 293 cells. Another paradigm involved co-transfection of the hLHR cDNA 
Table 1 Summary of binding and signaling parameters of YMGs and hLHR

Binding

$\mathrm{IC}_{50}(\mathrm{nM})$
$(n)$

Fusion proteins of YMGs and hLHR

$\mathrm{Y}(\mathrm{MG} 1 / \mathrm{LHR}) \quad 0.46 \pm 0.11$

(7)

Y(MG2/LHR)

$1.02 \pm 0.55$

(7)

hLHR

Y(CG/LHR $)$

$0.56 \pm 0 \cdot 15$

(5)

-
Signaling

\begin{tabular}{|c|c|c|c|}
\hline $\begin{array}{l}\mathrm{D}_{50}(\mathrm{nM}) \\
(n)\end{array}$ & $\begin{array}{l}\text { Basal cAMPa } \\
\text { (pmol/fmol) } \\
\text { (n) }\end{array}$ & $\begin{array}{l}\text { Basal cAMPa } \\
\text { (pmol/ml) } \\
(n)\end{array}$ & $\begin{array}{l}\text { Maximal cAMP } \\
(\mathrm{pmol} / \mathrm{ml}) \\
(\mathrm{n})\end{array}$ \\
\hline
\end{tabular}

$0.36 \pm 0.09$

(7)

$0.33 \pm 0.11$

(6)

$0 \cdot 26 \pm 0.04$

(7)

-c

$0.19 \pm 0.01$

(3)

(3)

$2 \cdot 24 \pm 1 \cdot 50$

(4)

YMG2 \& hLHR

$0.75 \pm 0.21$

(4)
$0.23 \pm 0.06$

(4)

$0.21 \pm 0.03$

(4)
$7.5 \pm 0.9^{b}$

(7)

$7.4 \pm 0.9^{b}$

(7)

$4 \cdot 9 \pm 0 \cdot 7$

(7)

-c

$11 \cdot 6 \pm 3 \cdot 6$

(3)

$10 \cdot 8 \pm 1 \cdot 5^{d}$

(4)

$7 \cdot 2 \pm 0 \cdot 7$

(4) (n)

$198 \pm 24$

(7)

$229 \pm 32$

(6)

$201 \pm 28$

(7)

$110 \pm 12 \cdot 5^{b}$

(6)

(7)

$5 \cdot 8 \pm 1 \cdot 3$

$338 \pm 91$

(3)

$6 \cdot 0 \pm 0 \cdot 7^{d}$

(3)

(4)

$4 \cdot 0 \pm 0 \cdot 4$

(4)

$114 \pm 21^{b}$

(4)
$307 \pm 40$

(4)

$265 \pm 70$

(4)

$173 \pm 63$

(4)

YhCG \& hLHR

$\underline{c}$

-

HEK 293 cells were transiently transfected with cDNAs to YMG1, YMG2, Y(MG1/LHR), and Y(MG2/LHR), with LHR serving as negative control and Y(CG/LHR) and YhCG \& LHR serving as positive controls. Dose-response curves were conducted with hCG, and competitive binding also included $50 \mathrm{pM}^{125} \mathrm{I}-\mathrm{hCG}$. The maximal cAMP levels refer to maximum production at $250 \mathrm{ng} / \mathrm{ml} \mathrm{hCG}$ with no correction for basal cAMP levels.

${ }^{a}$ Basal cAMP values are presented in two units: pmol/fmol of bound ${ }^{125} \mathrm{I}-\mathrm{hCG}$ to correct for expression levels, and pmol/ml. The former is relative and based on values of $B_{0}$ (see Materials and methods).

bSignificantly different from LHR $(P<0.05)$.

'Expression of yoked hCG-hLHR and co-expression of yoked hCG and hLHR results in minimal binding of ${ }^{125} \mathrm{I}-\mathrm{hCG}$ and in elevated levels of basal cAMP, compared with LHR, that are not further increased upon addition of exogenous hCG.

${ }^{\mathrm{d}} P<0.051$ when compared with LHR.

and cDNAs to the yoked mini-gonadotropins to evaluate non-covalent association at the relatively high intracellular concentrations of each component. In each experimental paradigm, negative controls consisted of just hLHR expression or mock transfection, while positive controls involved $\mathrm{Y}(\mathrm{CG} / \mathrm{LHR})$ expression and co-expression of YhCG and hLHR.

\section{Yoked mini-hCG-hLHR complexes: expression of a single chain ligand-receptor complex}

Addition of $50 \mathrm{pM}{ }^{125} \mathrm{I}-\mathrm{hCG}$ to cells expressing $\mathrm{Y}(\mathrm{MG} 1 / \mathrm{LHR})$ and $\mathrm{Y}(\mathrm{MG} 2 / \mathrm{LHR})$ led to specific binding similar to that of hLHR (Fig. 3A), presumably reflecting the low affinity of YMG1 and YMG2 to LHR. In contrast, cells expressing $\mathrm{Y}(\mathrm{GG} / \mathrm{LHR})$ bound negligible ${ }^{125} \mathrm{I}-\mathrm{hCG}$ as expected (Wu et al. 1996, Narayan et al. 2000a,
2002, Schubert et al. 2003), attributable to the nearly constant high-affinity association of singlechain hCG fused to hLHR. There was no significant specific binding of ${ }^{125} \mathrm{I}-\mathrm{hCG}$ to mocktransfected cells (data not shown), consistent with earlier reports (Wu et al. 1996, Narayan et al. 2002) and with data presented below. Transfected cells were incubated with an anti-LHR antibody, and receptor densities were then estimated by binding an ${ }^{125}$ I-labeled secondary antibody to an anti-LHR antibody. As shown in Fig. 3B, there is no significant difference in expression levels of hLHR, whether free or fused to YMG1, YMG2, or YhCG.

Competition binding curves, using ${ }^{125} \mathrm{I}-\mathrm{hCG}$ and hCG, are presented in Fig. 4A for cells expressing $\mathrm{Y}(\mathrm{MG} 1 / \mathrm{LHR}), \mathrm{Y}(\mathrm{MG} 2 / \mathrm{LHR})$, or hLHR. The $\mathrm{IC}_{50} \mathrm{~s}$ obtained from the three competition curves are essentially identical (Table 1). cAMP doseresponse curves were determined at various 
A.

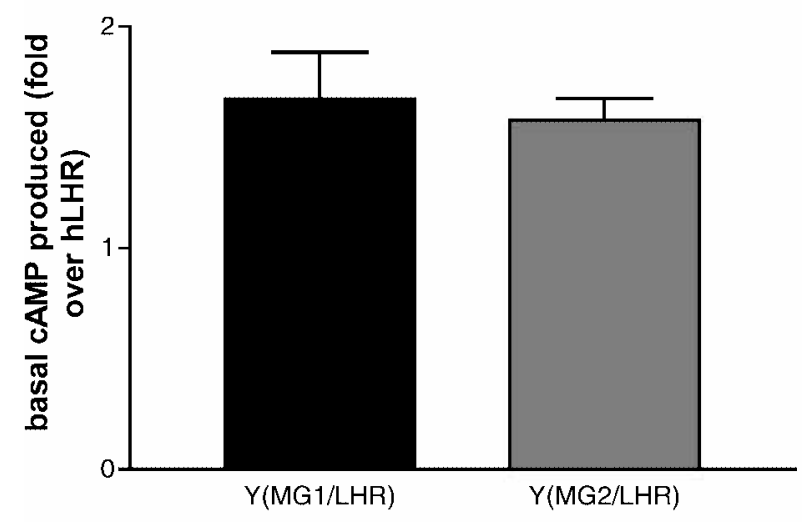

B.

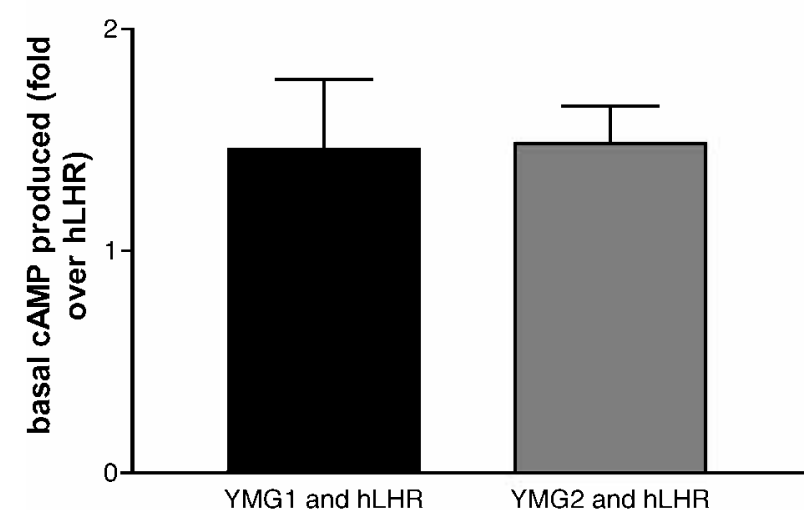

Figure 5 Basal cAMP production of HEK 293 cells expressing $Y(M G 1 / L H R)$ and $Y(M G 2 / L H R)$ and co-expressing YMG1 and hLHR and YMG2 and hLHR. (A) Results from cells expressing $Y(M G 1 / L H R)$ and Y(MG2/LHR); $P<0.05$ for each YMG fused to LHR. (B) Results from cells expressing YMG1 and hLHR and YMG2 and hLHR; $P<0.051$ for YMG2 and hLHR only. The results are an average of each individual experiment, shown as fold-increase over that of hLHR production. Averages were made from values expressed in pmol of cAMP produced/fmol bound ${ }^{125} \mathrm{I}-\mathrm{hCG}$, which is a relative correction for protein expression levels. Values are presented in Table 1.

concentrations of $\mathrm{hCG}$, and the $\mathrm{ED}_{50} \mathrm{~s}$ for Y(MG1/LHR), Y(MG2/LHR), and hLHR are also similar (Fig. 4B, Table 1). As expected from earlier studies (Wu et al. 1996, Narayan et al. 2000a, 2002, Schubert et al. 2003), $\mathrm{Y}(\mathrm{CG} / \mathrm{LHR})$ results in a high level of basal cAMP that is not further increased at high concentrations of exogenous hormone, and mock-transfected HEK 293 cells do not respond to exogenous hCG (Fig. 4B), consistent with the absence of LHR. Interestingly, the basal cAMP values of Y(MG1/LHR) and Y(MG2/LHR) are slightly elevated with reference to that of hLHR when corrected for expression levels, although only that for $\mathrm{Y}(\mathrm{MG} 2 / \mathrm{LHR})$ is significantly different from hLHR if these corrections are not made (Fig. 5A, Table 1).

\section{Yoked mini-hCGs and hLHR: co-expression of ligand and receptor}

Binding measurements with ${ }^{125} \mathrm{I}-\mathrm{hCG}$ suggested comparable receptor densities in cells expressing hLHR only and hLHR with each of the mini-hCGs (Fig. 6). Competition binding and cAMP activation curves show that $\mathrm{IC}_{50} \mathrm{~S}$ and $\mathrm{EC}_{50} \mathrm{~S}$ are similar in the hLHR control and when co-expressed with the YMGs. Co-expression of YhCG and hLHR results in a high basal level of cAMP that is not increased upon addition of hCG, analogous to that found with $\mathrm{Y}(\mathrm{CG} / \mathrm{LHR})$. These results are summarized in Fig. 7 and Table 1. Compared with hLHR and corrected for expression levels, the fold-increases in basal cAMP values are slightly greater in cells co-expressing hLHR and each of the minigonadotropins, but not significantly so (Fig. 5B). (In this paradigm, YMG2 co-expressed with hLHR differs from just expressed hLHR with a $P$ value of $<0.051$ whether the data are corrected for expression levels or not.)

\section{Discussion}

This work has shown that minimal activity is obtained from hCG $\beta$ fragments, consisting of amino acid residues $92-145$ and (92-109)-(115145), fused via the $\mathrm{C}$-terminus to the $\mathrm{N}$-terminus of the full-length $\alpha$-subunit when corrected for relative expression levels of the receptor. The low potencies of the analogs is emphasized by comparing the ratios of basal cellular cAMP concentrations in the expressed yoked ligand-hLHR and co-expressed ligand and hLHR systems to that of the hLHR control: the fold-increases were $1 \cdot 5-1 \cdot 6$ for the two mini-gonadotropins and roughly 30 for single chain $\beta \alpha$, whether yoked to or co-expressed with hLHR.

Nonetheless, the putative weak potencies of MG1 and MG2 may reflect specific effects of $\alpha$ and the 


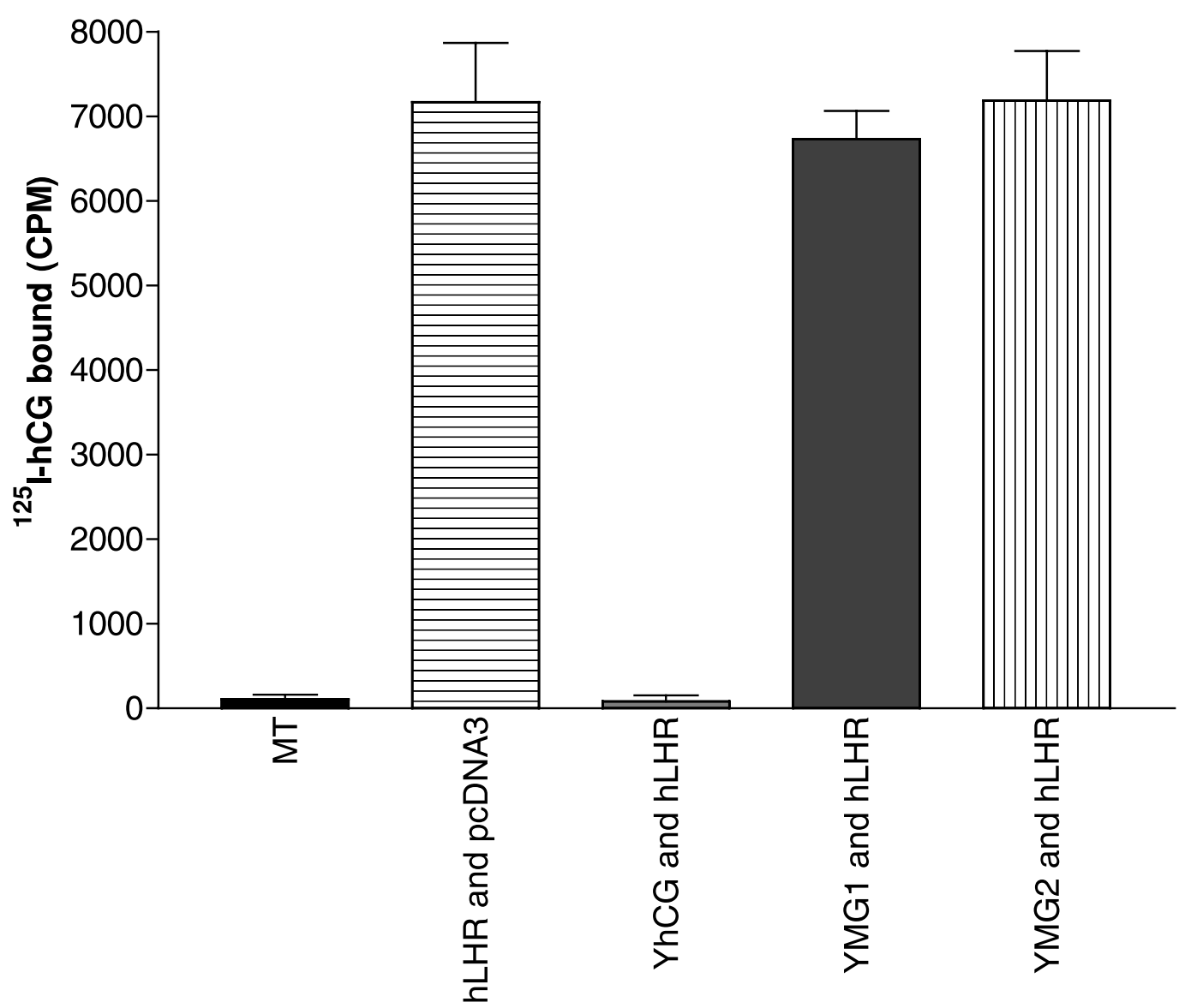

Figure 6 Cell surface expression of hLHR when co-expressed with yoked ligand-receptor complexes. Specific binding after addition of ${ }^{125}$-hCG to HEK 293 cells expressing hLHR or co-expressing hLHR and YMG1, YMG2, and YhCG. There is insignificant binding of ${ }^{125} \mathrm{I}$-hCG to mock-transfected (MT) cells, as expected (Wu et al. 1996, Narayan et al. 2002).

fused $\beta$ fragments. For example, recent studies from our laboratory found no evidence of intrinsic activity of full length $\alpha$ or hGG $\beta$ subunits when yoked to or co-expressed with rat LHR (Narayan et al. 2002). Controls were also run with prolactin and CTP yoked to rat LHR, and minimal increases in basal cAMP were observed; however, the limited numbers used in the experiment prohibited a statistical evaluation of these data. Clearly, potent hCG-based agonists and antagonists of the LH receptor will require a different protein engineering strategy, probably with the inclusion of different portions of the $\beta$-subunit rather than just the determinant loop-containing seat belt. Also, both subunits of hCG appear to contribute, either directly or indirectly, to LHR binding (Chen et al. 1991, 1992, Bielinski \& Boime 1992, Liu et al. 1993, Yoo et al. 1993, Puett et al. 1994); thus, portions of $\alpha$ and $\beta$ subunits will probably be required for potent single chain LHR agonists and antagonists.

Previous studies with heterodimeric hGG have shown that C-terminal fragments of hCG $\beta$, including des[122-145] $\beta$ (El-Deiry et al. 1989), $\operatorname{des}[115-145] \beta$ (Matzuk et al. 1990, Chen \& Bahl 1991), and des[111-145] $\beta$ (Huang et al. 1993a), associate well with $\alpha$ and the resulting heterodimers are equipotent to wild-type $\mathrm{hCG}$ in in vitro measurements. des[101-145] $\beta$ also bound to $\alpha$, but the heterodimer exhibited reduced potency; des [93$145] \beta$, on the other hand, failed to associate with $\alpha$ (Chen \& Puett 1991a). Two N-terminal deletion mutants of hCG $\beta$ have been described, $\operatorname{des}[1-7] \beta$ (Huang et al. 1993a) and des[2-8] $\beta$ (Slaughter et al. 1995). Although holoprotein formation was impaired in the latter, both deletion fragments bound $\alpha$, and the resulting heterodimers were 


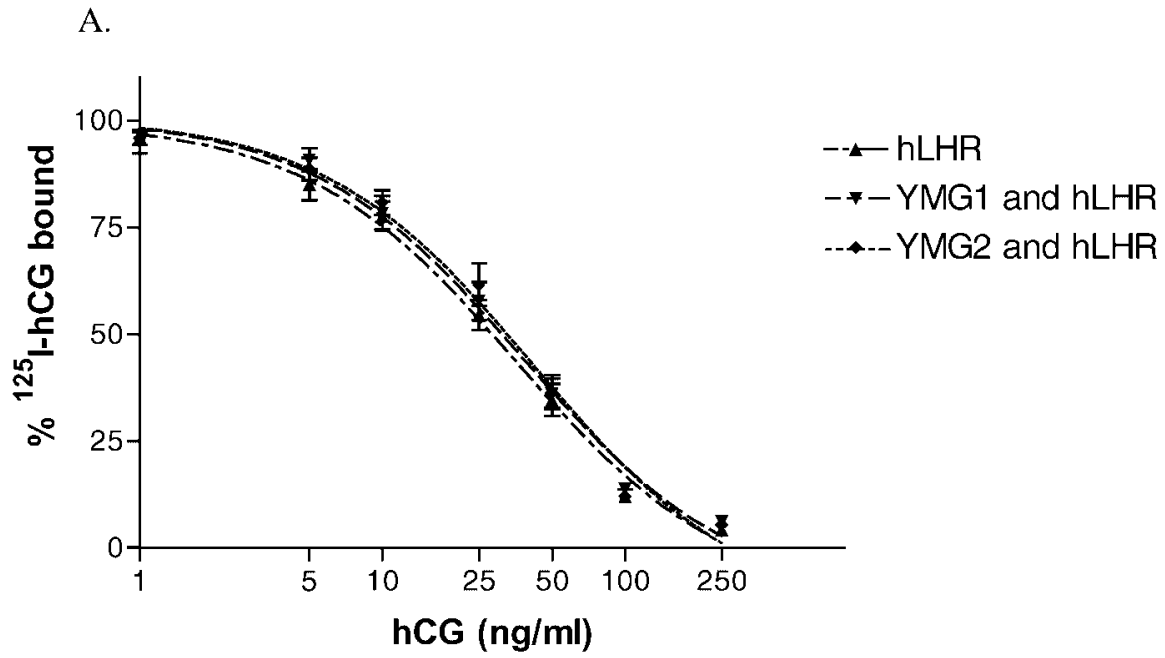

B.

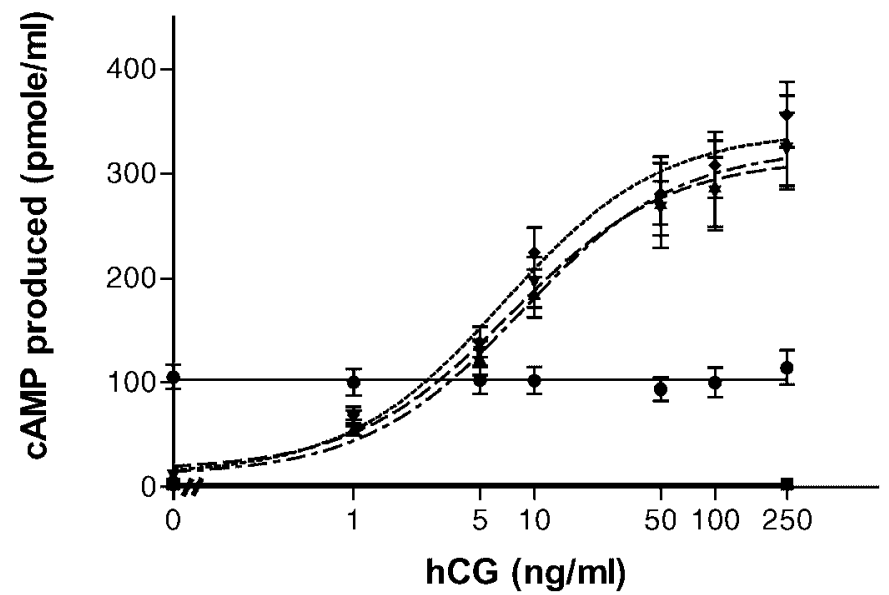

$\rightarrow-M T$

$--\curvearrowleft h L H R$ and pcDNA3

$\rightarrow$ YhCG and hLHR

$-\rightarrow-Y M G 1$ and $h L H R$

-.-- YMG2 and hLHR

Figure 7 Competitive binding and cAMP dose-response curves with HEK 293 expressing hLHR only or co-expressing hLHR with the yoked ligand-receptor complexes. (A) Competitive binding with $50 \mathrm{pM}{ }^{125} \mathrm{I}-\mathrm{hCG}$ and various concentrations of unlabeled hCG for hLHR alone and hLHR co-expressed with YMG1 and YMG2. (B) cAMP production in mock-transfected (MT) cells, in cells expressing hLHR only (hLHR and pcDNA3), and in cells co-expressing hLHR with YhCG, YMG1, and YMG2. The $I_{50} \mathrm{~S}$ and $\mathrm{EC}_{50} \mathrm{~s}$ are listed in Table 1.

equipotent to wild-type hGG. We also reported that a combined N-terminal and C-terminal deletion fragment of hCG $\beta$, des $[1-7,111-145] \beta$, bound to $\alpha$, resulting in a heterodimer equipotent to wild-type hCG, while des[1-7,101-145] $\beta$ associated poorly with $\alpha$, but some activity was present in the heterodimer (Huang et al. 1993a). A single chain $\mathrm{hCG}$ in the same configuration described here, i.e.
N- $\beta-\alpha-\mathrm{C}$, but with a shortened CTP, des[124$145] \beta$ was shown to be active (Narayan et al. 1995), as were fusion proteins of the form, des[103$145] \beta-(\text { Ser-Gly })_{\mathbf{x}}-\alpha$ and $\operatorname{des}[112-145] \beta-\left(\right.$ Ser-Gly) ${ }_{\mathbf{x}}-$ $\alpha$, where $\mathrm{x}=4,5$, or 6 (Heikoop et al. 1997).

The above studies, based on heterodimeric and single chain hCG derivatives, establish that the CTP does not contribute significantly to $\alpha$ 
association or receptor binding. It was, however, retained in our characterization of the mini-hCGs to serve as a spacer between the $\beta$ seat belt and the $\alpha$ subunit, as well as a linker between $\alpha$ and LHR in the yoked MG-LHR complexes. Prior to the present study, the shortest fragment of hCG $\beta$ that yielded some activity in vitro, in combination with $\alpha$, was des[1-7,101-145] $\beta$ (Huang et al. 1993a). The retention of the determinant loop was based on studies using synthetic peptides (Keutmann et al. 1989, Keutmann 1992), site-directed mutagenesis (Chen \& Bahl 1991, Chen \& Puett 1991b, Huang et al. 1993b), and protein chimeras (Campbell et al. 1991, Dias et al. 1994, Grossmann et al. 1997) suggesting this region of hCG $\beta$ to be important in receptor binding and activation, either directly or indirectly. While we have retained the determinant loop as part of the $\beta$ seat belt, we have, of course, no assurance that the Cys-93-Cys-100 disulfide forms in the MGs. Ben-Menahem et al. (1997) showed that engineered mutations of $\mathrm{Cys} \rightarrow \mathrm{Ala}$ at each of positions $\beta 93$ and $\beta 100$ in N-hCG $\beta-\alpha-C$ led to an hCG analog that was slightly less effective than wild-type single chain hCG. In this case, the determinant loop may be constrained in a native-like conformation.

Much less work has been carried out with deletions of the 92-amino acid residue $\alpha$-subunit. The C-terminal Ser can be removed without greatly impairing association with hCG $\beta$ and subsequent LHR binding and activation; however, progressive deletion of residues 91-92, 90-92, and 89-92 results in reduced signaling, while not eliminating receptor binding (Yoo et al. 1993). The N-terminal fragment, des[88-92] $\alpha$, associates with hCG $\beta$ but has reduced LHR binding and minimal signaling (Chen et al. 1992, Yoo et al. 1993). In contrast to these observations, the fusion protein, N-hCG $\beta$-des[88-92] $\alpha-\mathrm{C}$, was found to bind to LHR with the same affinity as the full-length control, but signaling was diminished (Sen Gupta \& Dighe 2000).

The suggestive finding of activity, albeit low, in the fusion proteins, N-des[1-91]hCG $\beta-\alpha-\mathrm{C}$ and $\mathrm{N}-\operatorname{des}[1-91,110-114] \mathrm{hCG} \beta-\alpha-\mathrm{C}$, offers promise for the design of mini-gonadotropins. Our data argue strongly, however, that potent hCG analogs, e.g. serving as agonists and antagonists, will require more of the $\beta$-subunit than just the determinant loop/seat belt. The results reported herein contribute to our understanding of hCG structure- function relationships and demonstrate the power of using fusion proteins to probe weak biological interactions.

\section{Acknowledgements}

We wish to thank John D Calhoun for his assistance with the preparation of the cDNAs for the miniaturized hCG $\beta$ subunits used to create the yoked mini-hGGs, Mike Ford for his help in preparing Fig. 2, Dr Patrick Roche for his generous gift of the anti-(rat LHR 15-38) antibody, and Dr Albert Parlow for providing purified hCG. We gratefully acknowledge all members of the laboratory, particularly Drs Krassimira Angelova, Lisa Kelly and Prema Narayans for their helpful suggestions and support.

\section{References}

Ascoli M, Fanelli F \& Segaloff DL 2002 The lutropin/ choriogonadotropin receptor, a 2002 perspective. Endocrine Reviews 23 141-174.

Ben-Menahem D, Kudo M, Pixley MR, Sato A, Suganuma N, Perlas E, Hsueh AJW \& Boime I 1997 The biologic action of single-chain choriogonadotropin is not dependent on the individual disulfide bonds of the $\beta$ subunit. Fournal of Biological Chemistry 272 6827-6830.

Ben-Menahem D, Jablonka-Shariff A, Hyde RK, Pixley MR, Srivastava S, Berger P \& Boime I 2001 The position of the $\alpha$ and $\beta$ subunits in a single chain variant of human chorionic gonadotropin affects the heterodimeric interaction of the subunits and receptor-binding epitopes. Fournal of Biological Chemistry $\mathbf{2 7 6}$ 29871-29879.

Bielinski M \& Boime I 1992 Site-directed mutagenesis defines a domain in the gonadotropin $\alpha$ subunit required for assembly with the chorionic gonadotropin $\beta$-subunit. Molecular Endocrinology 6 267-271

Campbell RK, Dean-Emig DM \& Moyle WR 1991 Conversion of human choriogonadotropin into a follitropin by protein engineering. PNAS 88 760-764.

Chen W \& Bahl OP 1991 Recombinant carbohydrate variant of the human choriogonadotropin $\beta$-subunit (hCG $\beta$ ) descarboxyl terminus (115-145). Fournal of Biological Chemistry 266 6246-6251.

Chen F \& Puett D 1991 a Delineation via site-directed mutagenesis of the carboxyl-terminal region of human choriogonadotropin $\beta$ required for subunit assembly and biological activity. Fournal of Biological Chemistry 26669046908.

Chen F \& Puett D $1991 b$ Contributions of arginines -43 and -94 of human choriogonadotropin $\beta$ to receptor binding and activation determined by oligonucleotide-based mutagenesis. Biochemistry $\mathbf{3 0}$ 10171-10175.

Chen F, Wang Y \& Puett D 1991 Role of the invariant aspartic acid 99 of human choriogonadotropin $\beta$ in receptor binding and biological activity. Foumal of Biological Chemistry 266 19357-19361.

Chen F, Wang Y \& Puett D 1992 The carboxy-terminal region of the glycoprotein hormone $\alpha$-subunit: contributions to receptor binding and signaling in human chorionic gonadotropin. Molecular Endocrinology 6 914-919. 
Dias JA, Zhang Y \& Liu X 1994 Receptor binding and functional properties of chimeric human follitropin prepared by an exchange between a small hydrophilic intercystine loop of human follitropin and human lutropin. Fournal of Biological Chemistry $\mathbf{2 6 9}$ 25289-25294.

Dufau ML 1998 The luteinizing hormone receptor. Annual Review of Biochemistry 60 461-496.

El-Deiry S, Kaetzel D, Kennedy G, Nilson J \& Puett D 1989 Site-directed mutagenesis of the human chorionic gonadotropin $\beta$ subunit: bioactivity of a heterologous hormone, bovine $\alpha$-human des-(122-145)ß. Molecular Endocrinology 3 1523-1528.

Fox KM, Dias JA \& Van Roey P 2001 Three-dimensional structure of human follicle-stimulating hormone. Molecular Endocrinology 15 378-389.

Fralish GB, Narayan P \& Puett D 2001 High-level expression of a functional single-chain human chorionic gonadotropin-luteinizing hormone receptor ectodomain complex in insect cells. Endocrinology $1421517-1524$.

Grossmann M, Szkudlinski MW, Wong R, Dias JA, Ji TH \& Weintraub BD 1997 Substitution of the seat-belt region of the thyroid-stimulating hormone (TSH) $\beta$-subunit with the corresponding regions of choriogonadotropin or follitropin confers luteotropic but not follitropic activity to chimeric TSH. Fournal of Biological Chemistry 272 15532-15540.

Han Y, Bernard MP \& Moyle WR 1996 hCG $\beta$ residues 94-96 alter LH activity without appearing to make receptor contacts. Molecular and Cellular Endocrinology 124 151-161 [erratum: 1997129 237-239].

Hearn MTW \& Gomme PT 2000 Molecular architecture and biorecognition process of the cysteine knot protein superfamily: part I. The glycoprotein hormones. Fournal of Molecular Recognition $13223-278$.

Heikoop JC, Van Beuningen-De VMM, Van Den Boogaart P \& Grootenhuis PDJ 1997 Evaluation of subunit truncation and the nature of the spacer for single chain human gonadotropins. European Fournal of Biochemistry 245 656-662.

Huang J, Chen F \& Puett D 1993a Amino/carboxyl-terminal deletion mutants of human choriogonadotropin. Fournal of Biological Chemistry 268 9311-9315.

Huang J, Ujihara M, Xia H, Chen F, Yoshida H \& Puett D $1993 b$ Mutagenesis of the 'determinant loop' region of human choriogonadotropin $\beta$. Molecular and Cellular Endocrinology 90 211-218.

Keutmann HT 1992 Receptor-binding regions in human glycoprotein hormones. Molecular and Cellular Endocrinology $\mathbf{8 6}$ C1-C6.

Keutmann HT, Mason KA, Kitzmann K \& Ryan RJ 1989 Role of the $\beta 93-100$ determinant loop sequence in receptor binding and biological activity of human luteinizing hormone and chorionic gonadotropin. Molecular Endocrinology 3 526-531.

Lapthorn AJ, Harris DC, Littlejohn A, Lustbader JW, Canfield RE, Machin KJ, Morgan FJ \& Isaacs NW 1994 Crystal structure of human chorionic gonadotropin. Nature 369 455-461.

Liu C, Roth KE, Shepard BA, Shaffer JB \& Dias JA 1993 Site-directed alanine mutagenesis of Phe33, Arg35, and Arg42-Ser43-Lys44 in the human gonadotropin alpha-subunit. fournal of Biological Chemistry 268 21613-21617.

Matzuk MM, Hsueh AJW, Lapolt P, Tsafriri A, Keene JL \& Boime I 1990 The biological role of the carboxyl-terminal extension of human chorionic gonadotropin $\beta$-subunit. Endocrinology 126 376-383.

Moore WT, Burleigh BD \& Ward DN 1980 Chorionic gonadotropins: comparative studies and comments on relationships to other glycoprotein hormones. In Chorionic Gonadotropins, pp 89-126. Ed. SJ Segal. New York: Plenum Press.

Narayan P, Wu C \& Puett D 1995 Functional expression of yoked human chorionic gonadotropin in baculovirus-infected insect cells. Molecular Endocrinology 9 1720-1726.

Narayan P, Gray J \& Puett D 2000 a A biologically active single chain human chorionic gonadotropin analog with altered receptor binding properties. Endocrinology $14167-71$.

Narayan P, Wu C \& Puett D $2000 b$ Genetic engineering of single chain gonadotropins and hormone-receptor fusion proteins. Methods 21 59-66.

Narayan P, Gray J \& Puett D 2002 Yoked complexes of human choriogonadotropin and the lutropin receptor: evidence that monomeric individual subunits are inactive. Molecular Endocrinology $162733-2745$.

Puett D \& Narayan P 2000 Designer gonadotropins and receptors: the prospect of recombinant technology. In Ovulation: Evolving Scientific and Clinical Concepts, pp 295-307. Ed. EY Adashi. New York: Springer-Verlag.

Puett D \& Narayan P 2002 Fusion proteins of human gonadotropins and gonadotropin receptor complexes. Indian Fournal of Experimental Biology $40415-423$.

Puett D, Huang J \& Xia H 1994 Delineation of subunit and receptor contact sites by site-directed mutagenesis of hCG $\beta$. In Glycoprotein Hormones, pp 122-134. Eds JW Lustbader, D Puett \& RW Ruddon. New York: Springer-Verlag.

Salesse R, Bidart J-M, Troalen F \& Garnier J 1990 Peptide mapping of intersubunit and receptor interactions of human choriogonadotropin. Molecular and Cellular Endocrinology 68 113-119.

Schubert RL, Narayan P \& Puett D 2003 Specificity of cognate ligand-receptor interaction: fusion proteins of hCG and the heptahelical receptors for human luteinizing hormone, thyroid-stimulating hormone, and follicle-stimulating hormone. Endocrinology 144 129-137.

Sen Gupta C \& Dighe RR 2000 Biological activity of single chain choriogonadotropin, $\mathrm{hCG} \alpha \beta$ is decreased upon deletion of five carboxyl terminal amino acids of the $\alpha$ subunit without affecting its receptor binding. Fournal of Molecular Endocrinology 24 157-164.

Slaughter S, Wang Y, Myers RV \& Moyle WR 1995 The lutropin $\beta$-subunit $\mathrm{N}$-terminus facilitates subunit combination by offsetting the inhibitory effects of residues needed for LH activity. Molecular and Cellular Endocrinology 112 21-25.

Sugahara T, Pixley MR, Minami S, Perlas E, Ben-Menahem D, Hsueh AJ \& Boime I 1995 Biosynthesis of a biologically active single peptide chain containing the human common alpha and chorionic gonadotropin beta subunits in tandem. PNAS 92 2041-2045.

Wu H, Lustbader JW, Liu Y, Canfield RE \& Hendrickson WA 1994 Structure of human chorionic gonadotropin at $2 \cdot 6 \AA$ resolution from MAD analysis of the selenomethionyl protein. Structure $\mathbf{2}$ $545-558$.

Wu C, Narayan P \& Puett D 1996 Protein engineering of a novel constitutively active hormone-receptor complex. Fournal of Biological Chemistry 271 31638-31642.

Yoo J, Zeng H, Ji I, Murdoch WJ \& Ji TH 1993 COOH-terminal amino acids of the alpha subunit play common and different roles in human choriogonadotropin and follitropin. Fournal of Biological Chemistry 268 13034-13042.

Received 3 March 2003

Accepted 8 May 2003 